\title{
O uso de informações de pesquisa de marketing pelas agências de comunicação do Vale do Paraíba - SP
}

\author{
Use of marketing research by advertising agencies of \\ Vale do Paraíba - SP \\ Flávia Chaves Valentim Rodrigues ${ }^{I}$ \\ (flaviacvalentim@hotmail.com) \\ Luis Fernando Zulietti ${ }^{2}$ \\ (zulietti.zulietti@gmail.com) \\ Monica Franchi Carniello3 \\ (monicafcarniello@gmail.com)
}

\begin{abstract}
Resumo
Os mercados publicitários do interior, com destaque ao estado de São Paulo, tem adquirido maior representatividade com o aumento dos investimentos em mídia, o que amplia a necessidade de maior profissionalização da gestão das agências. $O$ objetivo foi verificar como as agências de propaganda sediadas no Vale do Paraíba - SP fazem uso de informações geradas por pesquisa de marketing para tomada de decisão e fundamentação das campanhas publicitárias que desenvolvem para seus clientes. A pesquisa caracteriza-se como exploratória, de abordagem qualitativa, com coleta de dados por meio de entrevistas semi estruturadas com profissionais de agências de publicidade da região estudada. Verificou-se que os gestores das agências selecionadas como amostra compreendem a relevância da pesquisa de marketing, no entanto o uso ainda é limitado por questão de custos, falta de credibilidade em fornecedores regionais, falta de conhecimento dos anunciantes sobre pesquisa e pela ampla gama de informação pública existente.
\end{abstract}

Palavras-chave: Comunicação publicitária. Pesquisa de marketing. Agências de comunicação. Mercado regional.

\begin{abstract}
Regional advertising markets, especially in the São Paulo State, has acquired greater representation with media investments increasing, which magnifies the need for more professional management for the agencies. The goal was to determine how ad agencies based in the Vale do Paraíba - SP make use of information generated by marketing research for decision making and motivation of developing advertising campaigns for its customers. The research is characterized as exploratory, with qualitative approach and data collection through semi-structured interviews. It was found that the managers of the agencies selected as sample understand the importance of marketing research, but the use is still limited for reasons of cost, lack of credibility in regional suppliers, advertisers lack of knowledge about research and the wide range of public information.
\end{abstract}

Keywords: Marketing communication. Marketing research. Advertising agencies. Regional market.

\footnotetext{
${ }^{1}$ Mestre em Gestão e Desenvolvimento Regional - Universidade de Taubaté.

${ }^{2}$ Fundação Álvares Penteado - FAAP.

${ }^{3}$ Docente do Mestrado em Planejamento e Desenvolvimento Regional da Universidade de Taubaté.
}

Comunicação \& Informação, v. 16, n. 1, p. 45-61, jan./jun. 2013 


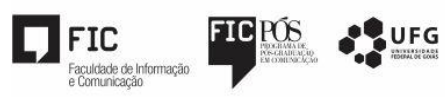

\section{Introdução}

$\mathrm{A}$ pesquisa mercadológica no Brasil se delineia nas décadas de 1940 e 1950, como reflexo da transformação produtiva brasileira, caracterizada, nesse período, pelo incremento da industrialização e ampliação dos mercados em função do intenso processo de urbanização. A influência norte-americana se estende para além do complexo industrial, incidindo também sobre aspectos culturais, padrões de consumo e a comunicação publicitária. No entanto, apesar da nítida influência, as agências de propaganda precisam adaptar seus argumentos para a realidade brasileira. Também nesse período os veículos de comunicação ganham nova dimensão com a instalação das emissoras de televisão a partir da década de 1950. Nesse cenário, as agências precisavam tomar decisões, e para isso passaram a recorrer à pesquisa mercadológica. Nascem os institutos de pesquisa, entre eles o IBOPE e o MARPLAN, que passam a fornecer dados para o mercado de comunicação. (MELO, 2007, p. 28).

A utilização de pesquisas mercadológicas, no entanto, foi incorporada de forma gradual e regionalmente heterogênea. "A fase pioneira - décadas de 30 e 40 - compreende alguns estudos esparsos realizados num período em que a propaganda do Brasil estava saindo de seu período romântico [...]". (EDUARDO, 1990, p. 98) O autor destaca também que da fase se desenvolvimento, localizada historicamente nas décadas de 1950 e 1960, o interesse pela pesquisa ainda era pequeno e limitado a reduzido número de agências e clientes. É a partir da década de 1970 que a pesquisa mercadológica no Brasil vive uma fase de amadurecimento (EDUARDO, 1990).

O próprio desenvolvimento da atividade publicitária no Brasil se deu de maneira heterogênea, com concentração das agências sediadas nas capitais ou grandes centros urbanos. É a partir da década de 1980 que os mercados do interior passam a ter uma participação mais representativa na atividade publicitária, dentre deles, de forma mais evidente, o interior do Estado de São Paulo. Segundo Lopes, (2006, p. 8), "a partir da regionalização da televisão e do estabelecimento do interior como centro produtivo do estado, com importância industrial, tecnológica, de ensino e do setor terciário, há espaço para o investimento em comunicação mercadológico e publicidade e propaganda".

Dentre os mercados regionais do estado de São Paulo, a mesorregião do Vale do Paraíba apresentou um representativo desenvolvimento da atividade publicitária a partir de 1980, com instalação de emissoras regionais afiliada da Rede Globo de televisão e da Bandeirantes, com 
concessão para comercialização de espaços publicitários regionais. A presença de veículos de comunicação com atuação regional é um fator de dinamização da atividade publicitária. "Isso parece indiscutível: os primórdios do negócio publicitário estão ligados ao veículo" (RAMOS, 1990, p.4).

Antes desse acontecimento, a malha de comunicação da região era primária, com grande número de profissionais formados em outras áreas, visto que era um mercado ainda em formação. Com a instalação da transmissora regional da Rede Globo e, subsequentemente, de outras emissoras, o mercado publicitário regional se transformou. Entre as mudanças, destaca-se a abertura e instalação de faculdades de comunicação por instituições de ensino superior do Vale do Paraíba, com o intuito de atender uma crescente demanda de profissionais.

Segundo Queiroz (2005), a introdução de cursos de bacharelado em Comunicação Social é um dos marcos que revela a consolidação da atividade publicitária nos mercados regionais. A partir desse fenômeno, a atividade publicitária consolidou-se gradualmente, ao mesmo tempo em que refletia o amadurecimento das atividades dos setores da economia, a saber, indústria, comércio e serviços.

Em função dessa reconfiguração do mercado, impulsionada pela consolidação da mídia televisiva na região, o que supostamente resultou no amadurecimento dos profissionais e, consequentemente, na profissionalização dos processos de gestão das agências de comunicação, o presente artigo teve como objetivo verificar como as agências de propaganda sediadas no Vale do Paraíba - SP fazem uso de informações geradas por pesquisa de marketing para tomada de decisão e fundamentação das campanhas publicitárias que desenvolvem para seus clientes.

Conforme Marcondes (2004, p.28), “[...] a pesquisa de marketing traz uma contribuição importantíssima, esclarecendo e resolvendo questões e optando entre decisões alternativas". O uso de informações geradas a partir de métodos de pesquisa desenvolvidos por institutos de pesquisa é um dos aspectos que pode mensurar o estágio de amadurecimento do mercado publicitário regional no que tange à profissionalização da gestão e na existência de fornecedores especializados na geração de informação de marketing - institutos de pesquisa - na cadeia produtiva do segmento.

\section{Referencial teórico}

\subsection{A pesquisa na cadeia produtiva de comunicação}


De acordo com Melo (1998), o desenvolvimento da pesquisa de propaganda no Brasil tem início nas décadas de 1940 e 1950 e reflete a modificação da estrutura produtiva brasileira, com o incremento da industrialização e do desenvolvimento de um mercado interno. Posteriormente a essa data, deu-se a etapa de desenvolvimento que acompanhou o progresso da propaganda nas décadas de 1950 e 1960, que se deu na mesma época que acontecia o processo de urbanização e o crescimento industrial do país.

Tal período coincide com o aprimoramento das estatísticas socioeconômicas de incumbência das instituições governamentais. Dessa forma, o país passa a contar com dados oficiais públicos que também colaboram para delinear mercados, públicos e desempenho econômico.

A partir desse período verifica-se a propagação, ainda que heterogênea e gradual, da pesquisa de marketing. Segundo Aaker, Kumar e Day, (2004, p.28), “[...] a pesquisa de marketing ajuda a melhorar as decisões empresariais, proporcionando informação relevante acurada e em tempo hábil”. Cada decisão precisa de informações específicas e únicas, e estratégias relevantes podem ser elaboradas tendo por base as informações colhidas pela pesquisa de marketing.

[...] pesquisa de marketing é a função que liga o consumidor, o cliente e o público ao "marketeiro", por meio de informações - informações estas utilizadas para identificar e definir oportunidades e problemas de marketing, gerar, aperfeiçoar e avaliar ações de marketing; monitorar o desempenho do marketing, e melhorar a compreensão do marketing como um processo". A pesquisa de marketing especifica as informações necessárias para abordar essas questões; formula o método para coleta de informações, administra e implementa o processo de coleta de dados, analisa os resultados, e comunica as descobertas e suas implicações. (MCDANIEL; GATES, 2001, p.08).

Tal afirmação permite inferir que o uso de informações de pesquisa está diretamente relacionada à consolidação do conceito de marketing nas empresas, que tem como premissa o consumidor como referencial para definir modelos de negócio. Para compreender o consumidor fazse necessário o uso de métodos de pesquisa para gerar dados primários.

Uma métrica é um sistema de mensuração que quantifica uma tendência, uma dinâmica ou uma característica. Em todas as disciplinas, os praticantes usam métricas para explicar fenômenos, diagnosticar causas, compartilhar descobertas e projetar os resultados de eventos futuros. As métricas estimulam o rigor e a objetividade. Elas tornam possível comparar observações entre regiões e períodos de tempo, facilitando a compreensão. (FARRIS, 2007, p.17). 


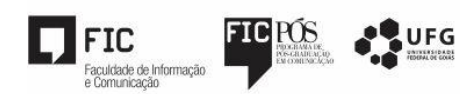

Se na perspectiva estritamente fordista as métricas focavam o desempenho da produção, em um ambiente competitivo cuja base conceitual é pautada no marketing deve ampliar as métricas para além dos limites das atividades internas da empresa para compreender o mercado, e o mercado é formado por pessoas, que demandam, por vezes, além da abordagem quantitativa uma abordagem qualitativa para serem compreendidas. Tal perspectiva revela a mudança de perspectiva das empresas de um orientação voltada prioritariamente para a produção para uma orientação voltada para o marketing.

A atividade de pesquisa no Brasil é autorregulamentada pela Associação Brasileira de Empresas de Pesquisa (ABEP), entidade não governamental, sem fins lucrativos, guardiã do Código Internacional de Ética em Pesquisa de Mercado, Opinião Pública e Social (ICC/ESOMAR) no país e dos padrões de qualidade da atividade.

As métricas de marketing podem servir tanto como indicadores de problemas como indicadores de oportunidades, que sendo bem aproveitadas, geram um melhor desempenho financeiro para a saúde das empresas, inclusive para os problemas, que, se bem resolvidos, revertem a situação negativa da empresa.

Geralmente as pesquisas são realizadas por institutos de pesquisa independentes, que, na cadeia produtiva da comunicação, são entendidos como fornecedores das agências de comunicação ou diretamente das empresas anunciantes.

A Figura 1 apresenta a estrutura da cadeia produtiva do segmento da comunicação publicitária, na qual estão inseridos os institutos de pesquisa.

Figura 1 - Cadeia produtiva da atividade publicitária 


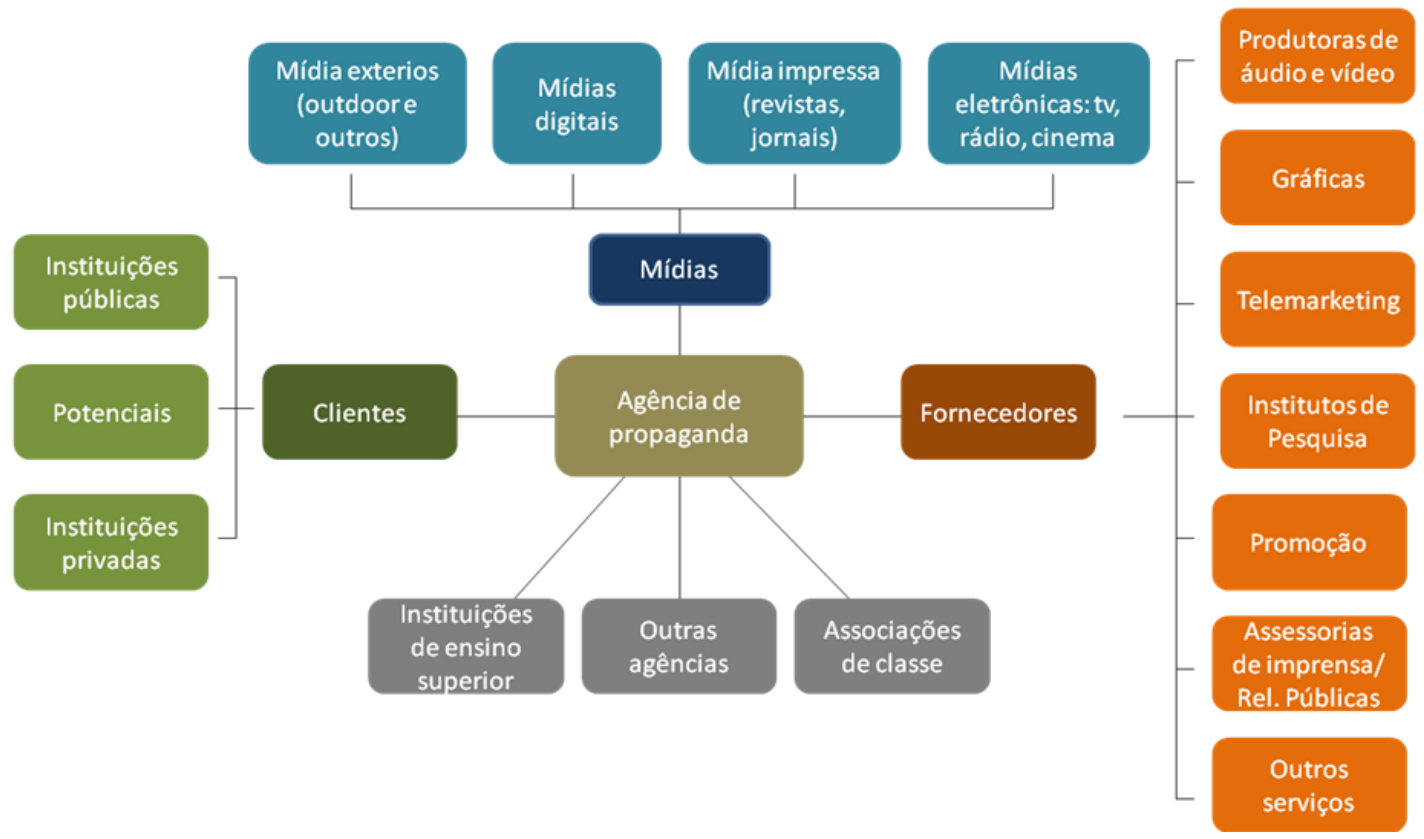

Fonte: Elaborado pelos autores a partir de Correa (2002).

Observa-se, na Figura 1, que a pesquisa aparece como um serviço correlato à atividade da agência. Para que haja demanda para os institutos de pesquisa, é necessário que as agências estejam estruturadas sob a perspectiva da gestão. Os institutos de pesquisa também atendem os chamados clientes diretos, empresas que contratam seus serviços sem o intermédio de uma agência. É exatamente esse papel de articulador entre institutos de pesquisa e clientes que se constitui o foco dessa pesquisa, cujo objetivo verificar como as agências de propaganda sediadas no Vale do Paraíba - SP fazem uso de informações geradas por pesquisa de marketing para tomada de decisão e fundamentação das campanhas publicitárias que desenvolvem para seus clientes. Tal postura reflete a estrutura e maturidade do mercado publicitário de uma região.

\subsection{Regionalização e profissionalização da atividade publicitária}

O Brasil, a partir da década de 1970, vivencia um processo de interiorização das atividades produtivas, até então concentradas prioritariamente nos grandes centros urbanos, em consonância com o intenso processo de urbanização do país. Municípios do interior adquirem estrutura e porte suficientes para receberem empresas que dinamizam as economias locais. Com a industrialização e suas consequências extrapolando o limite geográfico das capitais, os mercados publicitários regionais passam a se desenvolver. Compreende-se por mercado "um conjunto de clientes com 
renda disponível e uma necessidade específica a ser atendida por uma empresa" (LIMEIRA, 2007, p. 3), fenômeno que ocorre nas cidades médias do interior. Carniello (2010, p.809) apresenta um conceito de mercado regional

Quando os agentes econômicos e/ou grupos de consumidores potenciais estão concentrados em determinada área geográfica, temos o que se denomina mercado regional. Pela geração de emprego e renda oriundas das trocas de bens e serviços, é usual a aplicação do termo mercado regional para referir-se ao índice de empregos e aos segmentos da economia mais relevantes de uma região. Para definir o mercado regional quando nos referimos ao consumo de mídias, considera-se a área geográfica de cobertura dos veículos de comunicação. Utiliza-se também o termo mercado regional para definir a organização do mercado, ou seja, o conjunto de fornecedores, práticas adotadas, formas de comercialização e particularidades da região abordada.

O desenvolvimento dos mercados regionais atraiu o interesse dos grandes grupos de comunicação, que passaram a investir em mídia regional. Straubhaar (2007, p. 11) enfatiza que

A mídia local parece representar um nível de identidade e credibilidade na maioria das pessoas. Atualmente a mídia local continua mais ligada a jornais, revistas, músicas, rádios e internet, mas isso pode mudar com o barateamento das tecnologias, que faz com que a produção de TV seja cada vez mais viável.

Pela composição da atividade publicitária no Brasil, existe uma relação direta entre o desenvolvimento dos mercados publicitários e a presença de veículos de comunicação em uma região. Esse processo é evidenciado com a distribuição das retransmissoras e afiliadas dos canais de televisão nas regiões do país, que foram responsáveis por fomentar os mercados publicitários regionais ao abrir possibilidades aos anunciantes e agências em uma mídia de amplo alcance, penetração e cobertura. Silva (2006, p. 289) afirma que a regionalização da TV é uma tendência mundial:

A regionalização da televisão já era prevista por muitos estudiosos da comunicação, como sendo um fenômeno da década de 90 no Brasil. Elas chegariam com as tevês a cabo e as comunitárias, tão comuns nos EUA. O público sente necessidade de obter notícias rápidas e precisas sobre sua região, não apenas através de jornais impressos locais.

Tal fenômeno superou um movimento inicial da atividade publicitária brasileira, em sua origem prioritariamente concentrada no Rio de Janeiro e São Paulo e posteriormente ampliada para 
outras capitais. "No fim da década de 30, a revista Propaganda estimava em 56 o número de agências em funcionamento no Rio e em São Paulo" (REIS, 1990, p. 334).

A propaganda regional traz algumas especificidades, conforme destaca Carniello (2010, p. 975)

A propaganda regional caracteriza-se como vertente da comunicação mercadológica que possui público-alvo concentrado em determinada área geográfica, e, portanto veiculação regionalizada, o que lhe atribui algumas particularidades. Quanto à finalidade, não se diferencia da propaganda convencional, que tem por objetivo difundir idéias, produtos ou serviços [...]. Quanto à abrangência, por contemplar os objetivos de anunciantes locais, possui veiculação em uma área restrita, recorrendo aos jornais locais, mídia exterior, afiliadas das redes de televisão e emissoras de rádio. [...] Quanto à forma, a propaganda regional veiculada nos sistemas de mídia está sujeita ao uso dos formatos padronizados e pré-determinados pelos veículos de comunicação, que pouco se diferenciam entre os veículos nacionais e mesmo globais. No entanto, verifica-se a existência de formatos alternativos aos estabelecidos pela grande mídia, como uma maneira de fomentar o desenvolvimento do comércio de uma localidade ou região que não possui recursos financeiros para anunciar nos veículos da mídia regional. [...]. Quanto ao conteúdo, as mensagens da propaganda regional podem explorar características endógenas da região de abrangência da campanha. Se diferencia das campanhas globais ou nacionais que, ainda que fazendo adaptações em função das características das regiões, possuem uma diretriz única. [...] A propaganda regional permite a adequação do conteúdo às características culturais do público-alvo com mais coerência, pois, por ter um escopo menor, tende a ter menos heterogeneidade entre os receptores ou, no mínimo, ter alguns elementos de identificação mais evidentes entre eles (CARNIELLO, 2010, p. 975).

Peruzzo (2003, p. 12) defende que o regional ainda é pouco explorado, mas a comunicação caminha na direção da regionalização como alternativa de conteúdos segmentados e com uma relação de custo-benefício apropriada aos negócios regionais:

Descobriu-se o local/regional como nicho de mercado, um segmento com potencial de rentabilidade alta e ainda pouco explorado comercialmente. A crise financeira vivida pela mídia contribuiu para empurrar empresas de comunicação em direção da segmentação de mercado, forçando abrirem-se mais a regionalização da produção, em detrimento da estratégia anterior na qual a produção de conteúdos era basicamente centralizada nos grandes centros urbanos como as capitais de São Paulo e do Rio de Janeiro, e distribuída por todo o território nacional.

Para ilustrar a representatividade do mercado publicitário do interior de São Paulo, apresenta-se o Gráfico 1, que demonstra o investimento dos anunciantes nas televisões regionais do 
Vale do Paraíba. Como fonte, foram utilizados os dados do relatório fornecido pelo do IBOPE, referentes ao período que vai de 2003 até 2011.

Gráfico 1: Total do investimento publicitário em TV aberta no Vale do Paraíba

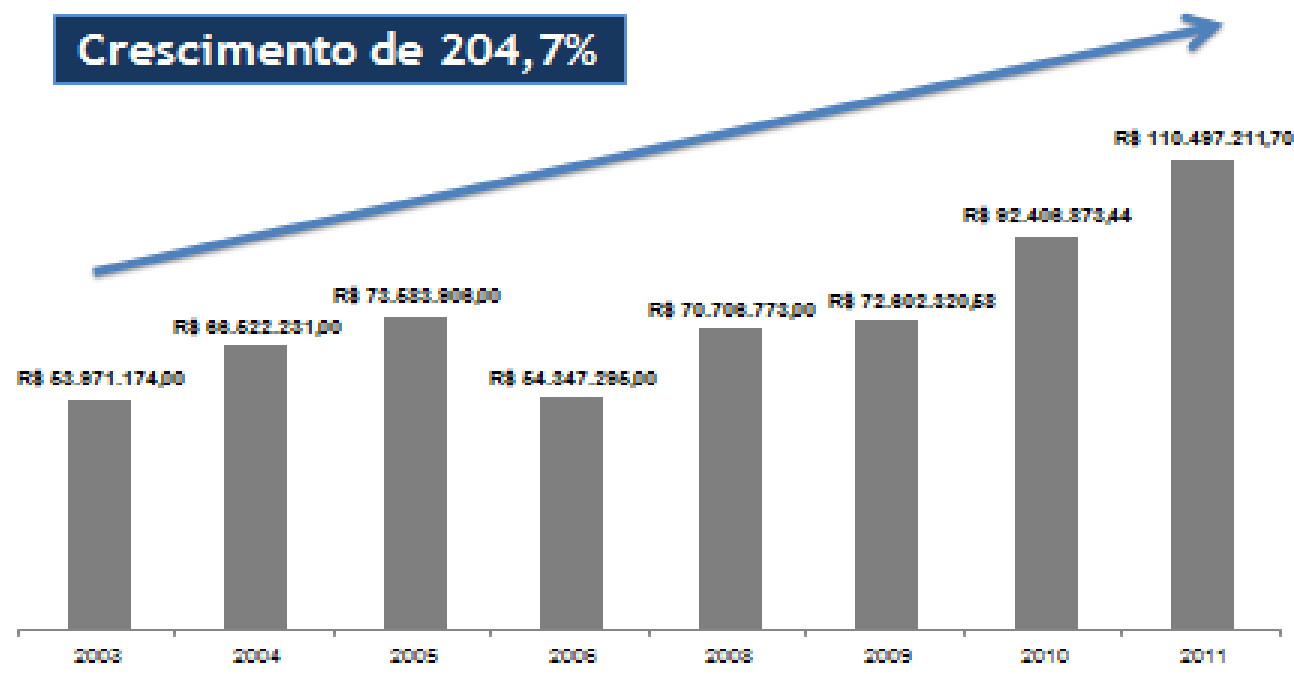

Fonte: Elaborado pelas autoras, com base em dados do IBOPE (2011).

Com representativo crescimento de investimentos, supõe-se que o mercado do Vale do Paraíba vivencia uma fase de consolidação e crescimento, o que se configura como um ambiente favorável para a contratação de serviços de institutos de pesquisa. Para a compreensão da dimensão do mercado publicitário regional, é apresentada a Tabela 1, que dimensiona as empresas componentes do segmento de comunicação.

Tabela 1 - Caracterização do mercado publicitário do Vale do Paraíba - SP

\begin{tabular}{lc}
\hline Agências certificadas pelo CENP & 38 \\
Gráficas & 50 \\
Emissoras de televisão (comerciais abertas, religiosas e universitárias) & 6 \\
Emissoras de rádio & 13 \\
Empresas de outdoor & 3 \\
Jornais & 4 \\
Institutos de pesquisa & $0^{*}$ \\
\hline
\end{tabular}

* Não foram encontrados institutos de pesquisa da região filiados à Associação Brasileira de Empresas de Pesquisa (APEP). No entanto, em buscas na Internet foram encontrados três institutos instalados na região do Vale do Paraíba, que não foram incluídos na Tabela 1 por não constarem em fonte institucionalizada/ oficial de consulta.

Fonte: elaborado pelos autores a partir de CENP (2011); Donos da Mídia (2011); Abigraf (2011), Abert (2011); ANJ (2011); Central de Outdoor (2011).

Comunicação \& Informação, v. 16, n. 1, p. 50-66, jan./jun. 2013 
É esse contexto comunicacional da mesorregião do Vale do Paraíba que se constituiu como locus dessa pesquisa.

\section{Método}

Quanto ao tipo de pesquisa, o presente trabalho caracteriza-se como pesquisa exploratória quanto ao objetivo, pautada em uma amostra selecionada por julgamento. Na abordagem da pesquisa, foram utilizadas técnicas de pesquisa com abordagem qualitativa. Foram entrevistados profissionais de agências de publicidade e propaganda do Vale do Paraíba, a fim de compreender o uso da informação advinda da pesquisa. Foram selecionados profissionais que atuam em agências localizadas no Vale do Paraíba que fossem certificadas pelo CENP. O total de agências certificadas em 2011 era 38 (CENP, 2011), o que compôs o universo da pesquisa. Desse universo, foram entrevistadas 11 agências, pelo critério de acessibilidade, visto que todas as agências foram contatadas.

\section{Resultados e discussão}

A partir das entrevistas realizadas, foi possível compreender como se dá a utilização de informações geradas por pesquisa de marketing pelas agências de comunicação da região do Vale do Paraíba.

Ao serem questionados sobre as fontes de informação utilizadas para tomada de decisão, verifica-se a priorização da utilização de dados secundários e dados públicos disponíveis, gerados por instituições do segmento de mercado em questão - associações, sindicatos. A contratação de pesquisas para gerar dados primários foi mencionada por três entrevistados, mas a falta de verba se mostra como uma barreira para a contratação de institutos de pesquisa.

Por meio de dados secundários e muito raramente terceirização de pesquisa (E6).

[...] Compramos revistas, como anuário de mídia, em que vem uma boa fonte de pesquisa para a área. Assim como para a área de jornalismo, assinamos conteúdo fechado para poder receber informações importantes em primeira mão. Quando é viável, buscamos realizar pesquisas qualitativas e quantitativas, mas nem sempre a verba disponível nos permite tal artifício (E7).

Pela totalidade da fala dos entrevistados, verifica-se que as agências deixam para último plano a contratação de institutos de pesquisa, ou seja, primeiramente elas buscam conhecer o 
cliente, seu segmento, seu mercado, depois se baseiam em dados secundários obtidos de pesquisas na web e bibliografias específicas e, por último, a contratação de um instituto de pesquisa, se necessário.

Apesar da baixa utilização de pesquisas por parte das agências, todos os entrevistados reconhecem que informações sobre o mercado fundamentam as ações das agências e aumentam a assertividade das campanhas.

Com certeza, a pesquisa normalmente vai te apontar, vai te dar embasamento, informação para que você tome uma atitude de uma forma mais correta, pois nem sempre você tem as informações tão claras, tão precisas (E5).

Sem dúvida, a agência já contratou pesquisa de institutos de pesquisa quando não conseguimos buscar a informação em dados secundários, e, fundamentalmente, a informação te dá diretriz, norteio (E6).

Fundamentais, a informação é fundamental; nada pode ser feito sem o processo adequado de recolhimento e de busca de informação, mas hoje recolher é possível (E4).

Pela fala dos entrevistados, nota-se que o recurso de contratação de um instituto de pesquisa só é considerada quando as informações públicas existentes não são suficientes para a tomada de decisão. A disponibilidade de informações, característica da atualidade e viabilizada pela comunicação digital estruturada em rede é um facilitador para as agências de propaganda na obtenção de dados do mercado para tomada de decisão. Esse contexto permite avaliar que o escopo de atuação de um instituto de pesquisa está em duas frentes: gerar informações de alta especificidade das empresas, por meio de pesquisas personalizadas (ad hoc) e gerar dados de interesse geral de segmentos de mercado, que possam ser comercializados em ampla escala (pesquisas omnibus) ou viabilizadas por instituições e/ou associações de classe ou setor.

Todos os entrevistados destacam categoricamente que a pesquisa ajuda a fundamentar tomada de decisão. "Objetividade, direcionamento, precisão na tomada de decisão, de escolha de mídias, de escolha de estratégias" (E6). Observa-se que os resultados de pesquisa são vistos como inquestionáveis, corretos. Não apareceu questionamento algum sobre método de pesquisa ou credibilidade dos instituto de pesquisa.

Quanto a baixa contratação de institutos de pesquisa, as agências atribuem aos clientes a não utilização de pesquisas primárias. 
Geralmente, os clientes não contratam pesquisas em função dos custos (E1).

Hoje eu não utilizo, eu já utilizei da prefeitura, os empresários acham que entendem do negócio, que estão no negócio há muito tempo e que não precisam pagar por informações (E2).

A pesquisa é uma coisa cara, não é qualquer cliente que se dispõe a fazer um investimento em uma pesquisa (E5).

Um por cento, pois nós estruturamos uma lógica de fazer um planejamento, mas tem momentos que precisa mesmo de uma pesquisa, mas a cultura é muito difícil aqui no mercado, e quando você tem clientes maiores eles te passam a pesquisa; então pra mim, já é um dado secundário, até por que não temos parceiros estabilizados para isso, você precisa de empresas boas na região; quando falamos de instituto de pesquisa no vale do Paraíba, não me lembro de nenhum (E4).

Por meio de respostas mencionadas no quadro anterior, entende-se que as agências da região do Vale do Paraíba não têm costume de praticar a indicação de pesquisa, com exceção das grandes agências, por terem um conceito formado sobre os empresários da região de que eles sabem de todas as informações relacionadas ao seu mercado e de que não querem pagar por essas informações ou, até mesmo, de que elas (as agências) preferem que seu cliente otimize a verba disponível para a mídia, suprindo a necessidade de informação apenas com a pesquisa de dados secundários e interpretando esses dados de forma a julgar interessante; além disso, ainda aponta que é difícil se lembrar de institutos renomados na região do Vale do Paraíba, o que dificulta a contratação de determinado serviço.

A busca de informações é de responsabilidade de distintos profissionais na agência. Em muitos casos, o proprietário da agência, frequentemente responsável pelo planejamento, assume a tarefa de buscar informações sobre o mercado. Em outros casos, é o profissional de atendimento que se encarrega pela busca de informações. Também os profissionais de mídia costumam buscar informações sobre veículos e audiência.

Nas poucas situações em que as agências contrataram institutos de pesquisa, ficaram satisfeitos com os resultados. Tratando-se de pesquisa de dados secundários, todas elas fazem por si próprias, tendo um profissional sempre incumbido de outras tarefas, mas que realiza mais essa função, e os resultados, na opinião das agências trazem dados relevantes para a tomada de decisão; porém, conforme mencionado pelo entrevistado 5, "cabe às agências a capacidade de interpretação dos dados, percebendo brechas no mercado que esses dados trarão.”

Comunicação \& Informação, v. 16, n. 1, p. 50-66, jan./jun. 2013 


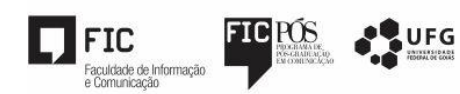

As opiniões dos profissionais das agências são bem divergentes com relação à orientação dada aos clientes sobre a importância da contratação de instituto de pesquisa; existe agência que orienta, porém já tem a ideia pré-concebida de que o serviço é caro e que o cliente provavelmente não aceitará investir, e agência que apenas orienta com o intuito de tirar de sua responsabilidade algo que não sairá corretamente.

Com relação à visão dos anunciantes, pesquisa é bom, importante e caro; já na opinião de profissionais de agências, a pesquisa deveria ser divulgada para as empresas, os institutos devem se mostrar mais, mostrar para as empresas que podem ser contratados, que estão presentes no mercado regional de maneira que possam solucionar os problemas das empresas, indo atrás da informação que falta para a compreensão de uma determinada situação.

Quando necessitam de contratação de pesquisa de dados primários todas, as agências contratam institutos de pesquisa; porém, tratando-se de pesquisa de dados secundários, todas elas fazem por si próprias, tendo um profissional sempre incumbido de outras tarefas, mas que realiza mais essa função.

\section{Considerações finais}

As agências de comunicação da região do Vale do Paraíba estão, no geral, ainda desacreditadas da existência de um instituto de pesquisa da região com credibilidade e com o intuito de trabalho em parceria. Elas entendem a necessidade de uma pesquisa bem elaborada de dados primários para a busca de informação precisa, porém, pela realidade apresentadas por elas sobre a cultura dos empresários da região, há de se acreditar que é preferível buscar apenas informações de dados secundários e saber interpretá-los do que investir altos valores na busca por dados primários. As fontes de informação que elas se apoiam para busca de dados secundários são: internet, televisão, revistas, jornais, associações de classe, sindicatos, prefeituras e mídias segmentadas. Para as agências, a busca por dados primários é efetivamente realizada quando realmente não há opção de saída, uma válvula de escape, ou como descobrir o problema do cliente; além disso, ainda tem de passar pela aprovação de valores - sendo estes considerados altos pelas agências -, de orçamentos elevados, não que não mereçam ser pagos, mas porque são caros, custosos. Cinco das sete agências entrevistadas já se utilizaram de pesquisa contratada por institutos, e duas delas nunca usaram. No entanto, das cinco agências, uma utilizou apenas uma vez em 16 anos de existência, e as outras quatro afirmaram que já usaram mais de uma vez para seus grandes clientes, número que não atinge 
$10 \%$ das carteiras de clientes atendidos por essas agências. Como foco principal das agências, a busca por informações se resume em pesquisar o negócio do cliente por meio de dados secundários, seus concorrentes, mercado, pesquisas publicadas pelos veículos de comunicação e público-alvo, muito raramente passando pela contratação de um instituto de pesquisa, somente em último caso. Conforme comentado pelas agências, quando utilizados, os tipos de pesquisa foram: avaliação de ponto para construção de empreendimento imobiliário, aceitação de marca, lembrança da marca e potencial de público-alvo.

Como mencionado anteriormente, somente as grandes agências da região têm o costume de praticar a indicação de pesquisa; no entanto, apontam que é difícil se lembrar de institutos renomados na região do Vale do Paraíba, fato que dificulta a contratação de determinado serviço. Levantam-se nesta dissertação, cinco institutos de pesquisa estabelecidos na região do Vale do Paraíba, três em São José dos Campos e dois em Taubaté. Identificam-se também os principais atores do mercado de comunicação do Vale do Paraíba, tornando-se uma ótima fonte de consulta para as agências de publicidade.

Nenhuma das agências entrevistadas possui um profissional exclusivo para o desenvolvimento de busca de informação, mas todas, sem exceção, possuem um profissional que também fica incumbido pela busca de informação; na maioria das vezes, são profissionais de planejamento que buscam por informações ou detectam a necessidade da busca por dados primários; entretanto, justifica-se na defesa de que o pagamento de um profissional especificamente para busca de informação não é condizente com o investimento; em algumas delas, a busca por informações é realizada também pelo atendimento e mídia, dependendo da estrutura física de cada agência.

Assim, conclui-se que falta por parte das agências dar crédito aos institutos de pesquisa da região, acreditar mais no fator da busca por dados primários e na importância dos pontos positivos proporcionados pela pesquisa, além do direcionamento das ações estratégicas, que proporcionará às agências uma assertividade em suas ações, resultando em credibilidade, visibilidade e crescimento para as agências e aos institutos de pesquisa. Cabe-se divulgar mais, aparecer, visitar as agências de publicidade, ir à busca de parcerias, se apresentar ao mercado, instruir clientes e ter acessibilidade.

Artigo submetido em 13/06/2013 e aceito em 28/08/2013.

\section{Referências}

AAKER, D; KUMAR, V; DAY, G. Pesquisa de Marketing. São Paulo: Atlas, 2004.

Comunicação \& Informação, v. 16, n. 1, p. 50-66, jan./jun. 2013 
ABEP. Associação Brasileira de Empresas de Pesquisa. Disponível em: 〈www.abep.com.br〉. Acesso em: 2 ago. 2011.

ABERT. Associação Brasileira de Emissoras de Rádio e Televisão. Disponível em: <www.abert.org.br/>. Acesso em: 2 ago. 2011.

ABIGRAF - Associação Brasileira da Indústria Gráfica. . Disponível em: <www.abigraf.org.br/>. Acesso em: 2 ago. 2011.

ANJ. Associação Nacional de Jornais. Disponível em: <www.anj.org.br/>. Acesso em: 2 ago. 2011.

CARNIELLO, Monica Franchi. Mercado regional. Enciclopédia Intercom de Comunicação. São Paulo: Intercom, 2010. p. 809-810.

CARNIELLO, Monica Franchi. Propaganda regional. Enciclopédia Intercom de Comunicação. São Paulo: Intercom, 2010. p. 975-976.

CENP. Conselho Executivo de Normas Padrão. Disponível em: 〈http://www.cenp.com.br >. Acesso em: 06 mar. 2011.

CENTRAL DE OUTDOOR. Disponível em: <www.outdoor.org.br>. Acesso em: 06 mar. 2011.

CORREA, R. Planejamento de propaganda. São Paulo: Global, 2002.

DONOS da mídia. Disponível em: <http://www.donosdamidia.com.br>. Acesso em: 7 set. 2011.

EDUARDO, O. da C. O desenvolvimento da pesquisa de propaganda no Brasil. In: BRANCO,

R.C.; MERTENSEN, R.L.; REIS, F. História da propaganda no Brasil. São Paulo: T.A.Queiroz, 1990.

FARRIS, P; BENDLE, N; PFEIFER, P; REIBSTEIN, D. Métricas de Marketing: Mais de 50 Métricas de todo executivo deve dominar. São Paulo: Bookman, 2007.

IBOPE. Disponível em: <http://www.ibope.com.br/calandraWeb/servlet/Calandra

Redirect?temp=0\&proj=PortalIBOPE\&pub=T\&db=caldb>. Acesso em: 10 jun. 2011.

LIMEIRA, Tania Maria Vidigal. E-marketing: o marketing na internet com casos brasileiros. São Paulo: Saraiva, 2007.

LOPES, E. E. F. Diagnóstico do sistema regional de produção publicitária (SRPP) na sociedade pós-industrial. In: CONGRESSO BRASILEIRO DE CIÊNCIAS DA COMUNICAÇÃO, 29., 2006, Brasília, DF. Anais do Intercom. Brasília, DF: UNB, 2006. Disponível em: <http://www.portcom.intercom.org.br/pdfs/68871772946643404973086570302323036698.pdf>. Acesso em: 10 out. 2012.

MARCONDES, P. APP 70 anos. São Paulo: Cip Brasil, 2007.

Comunicação \& Informação, v. 16, n. 1, p. 50-66, jan./jun. 2013 
MCDANIEL, C; GATES, R. Pesquisa de Marketing. São Paulo: Thompson, 2001.

MELO, J. M. de. Teoria da Comunicação: paradigmas latino-americanos. Petrópolis: Editora Vozes, 1998.

MELO, J. M. de. Panorama brasileiro da pesquisa em comunicação. In: BARBOSA, M.

Vanguarda do pensamento comunicacional brasileiro: as contribuições da Intercom (19772007). São Paulo: Intercom, 2007.

PERUZZO, Cicilia M. Krohling. Mídia local e suas interfaces com a mídia comunitária. In: CONGRESSO BRASILEIRO DE CIÊNCIAS DA COMUNICAÇÃO, 26., 2003, Belo Horizonte. Anais eletrônicos. São Paulo: Intercom, 2003.

QUEIROZ, A. O ensino de publicidade no Brasil. In: SILVA, Robson Bastos; PERUZZO, Cicília M. Krohling. Retrato do ensino em comunicação no Brasil. São Paulo: INTERCOM, Taubaté: UNITAU, 2005.

RAMOS, R. 1500-1930. Vídeo clipe das nossas raízes. In: BRANCO, R.C.; MERTENSEN, R.L.; REIS, F. História da propaganda no Brasil. São Paulo: T.A.Queiroz, 1990.

SILVA, Robson Bastos da. Limites e possibilidades da TV regional. In: MARQUES DE MELO, José; SOUSA, Cidoval Morais de; GOBBI, Maria Cristina (Orgs.). Regionalização midiática: estudos sobre comunicação e desenvolvimento regional. Rio de Janeiro: Sotese, 2006. p. 289-295.

STRAUBHAAR, Joseph. Caminhos glocais para a televisão. Intercom - Revista Brasileira de Ciências da Comunicação, São Paulo, v. 30, n. 2, p. 181-191, jul./dez. 2007. 